\section{Recommendations for hamstring injury prevention in elite football: translating research into practice}

\author{
Matthew Buckthorpe, ${ }^{1,2,3}$ Steve Wright, ${ }^{1}$ Stewart Bruce-Low, ${ }^{1}$ \\ Gianni Nanni, ${ }^{4}$ Thomas Sturdy, ${ }^{1}$ Aleksander Stephan Gross, ${ }^{1}$ \\ Laura Bowen, ${ }^{1}$ Bill Styles, ${ }^{1}$ Stefano Della Villa, ${ }^{2}$ Michael Davison, ${ }^{3}$ \\ Mo Gimpel ${ }^{1}$
}

\section{INTRODUCTION}

Injuries in football exert negative impacts on team performance ${ }^{1}$ and club finance. ${ }^{2}$ Hamstring strain injuries (HSI) are consistently the most prevalent time loss injury in football ${ }^{3}$ and as such are an important issue in football medicine. Despite an ever-increasing wealth of information emerging on the aetiology of HSIs, their incidence in football is increasing. ${ }^{3}$ This could be explained by the increased intensity and physical demands of football match play over the last decade $^{4}$; but practitioners should also question their approach to injury prevention and physical preparation of players, an area where research is lacking. ${ }^{5-8}$

There is an evidence-based strategy to prevent HSIs, however, there appears to be a large disconnect between this available evidence and its adoption in elite football. ${ }^{5} 6$ For example, the Nordic hamstring exercise (NHE) programme has been shown to effectively reduce HSIs by $65 \%-70 \% .^{9}{ }^{10}$ But recent surveys of elite European Champions League $(n=32)$ and Norwegian Premier League $(n=18)$ teams showed that only $11 \%$ of these teams fully adopt the programme. ${ }^{11}$

Within elite football, there is a large disconnect between evidence-based practice and the actual interventions used by science and medical teams to prevent injuries. $^{12}$ In line with an emerging body of evidence-based research, we believe that preventing HSIs in elite football requires a holistic approach, which considers multiple

\footnotetext{
'Southampton Football Club, Southampton, UK 2Isokinetic Medical Group, Education and Research Department, FIFA Medical Centre of Excellence, Bologna, Italy

${ }^{3}$ Isokinetic Medical Group, FIFA Medical Centre of Excellence, London, UK

${ }^{4}$ Isokinetic Medical Group, FIFA Medical Centre of Excellence, Bologna, Italy
}

Correspondence to Dr Matthew Buckthorpe, Isokinetic Medical Group, FIFA Medical Centre of Excellence, London WG1 9PF, UK;

M.Buckthorpe@isokinetic.com risk factors and their inter-relations, implemented effectively. ${ }^{6-8} 13$ In designing our injury prevention programme, we combine both the theory and the available evidence on HSI risk factors and intervention studies, as well as considering the context surrounding the player when designing our overall injury prevention approach.

\section{IMPORTANT CONSIDERATIONS WHEN} DESIGNING AN INJURY PREVENTION Why do HSIs happen? Risk factor analysis and programme planning To prevent HSIs, it is important to understand why they occur, so that an appropriate intervention can be developed, targeted at the specific risk factors. Importantly, there is not a clear understanding of why HSIs happen. Although there is a wealth of research examining HSI risk factors, there is a lack of evidence reporting consistent prospective risk factors for HSIs, ${ }^{14-16}$ and also a lack of research examining how the supposed risk factors interact with one another. ${ }^{717}$ Despite the difficulties of studying the interactions of multiple risk factors, it appears that risk factors do not operate in isolation, but instead function as a complex web of determinants. ${ }^{17}$ As such, our first approach when designing an HSI prevention programme is to consider all the possible risk factors which may be implicated, blending theory, evidence and anecdotal experiences (see figure 1).

Table 1 depicts the approach of our practitioners when considering the contents of the programme. It contains the list of risk factors linked in some way to HSIs, either through prospective or retrospective research studies, or from anecdotal evidence from within our group. Clearly, when designing a programme, one cannot specifically target every possible risk factor or assign equal weight to all risk factors. Instead, it is essential to rank the factors in order of importance PROGRAMME IN ELITE FOOTBALL considering both specific and general risk. This is by no means an exhaustive list, nor do we suggest that any of the risk factors displayed are permanently associated with the table category (eg, acute:chronic workload ratio (ACWR) could in some cases be moved to any of the other categories depending on the overall factors presented by the player). In our experience, those risk factors presented in the 'Recognised but does not inform normal practice' category are explored in more complex/detailed cases of preventing HSI. Multidisciplinary team-mediated player discussion in preseason serves to inform an individual's programme design and resource allocation.

\section{Gain key stakeholder buy-in}

Successful preparation and acting on player-related recommendations in professional football are highly dependent on 'buy in' from key decision makers (coaches, players and chief executive officers). ${ }^{18}$ Coaches exert influence on injury risk, ${ }^{19}$ and as such, any injury prevention strategy needs to have their support. The Sports Medicine and Science department should seek to understand the expectations that coaches and management staff have of them; and medical and performance strands should explore how the coaching team prefer to receive information (eg, chunking information, succinct messages, diagrammatic methods). Furthermore, the support staff implementing an injury prevention strategy should be mindful of how important education and communication is. ${ }^{20}$ The fundamental principles which may be obvious to the practitioner should be put into the context of each of the audiences they are dealing with to aid in an understanding of the process. With open and honest discussion and two-way communication, there will be an opportunity to feed into the injury prevention process and ensure it is the best fit for the individual.

\section{Target the interventions at the} individual player

We believe an essential element of HSI prevention programmes is the individualisation of the programme, targeted at the individual's injury risk profile. Players are typically screened by the Sports Medicine and Science department for health evaluations, musculoskeletal evaluations, athleticism (eg, strength, speed, power and agility), psychological profile, injury history, neuromuscular control/movementquality and hamstring strength, typically at the start of each season. This 


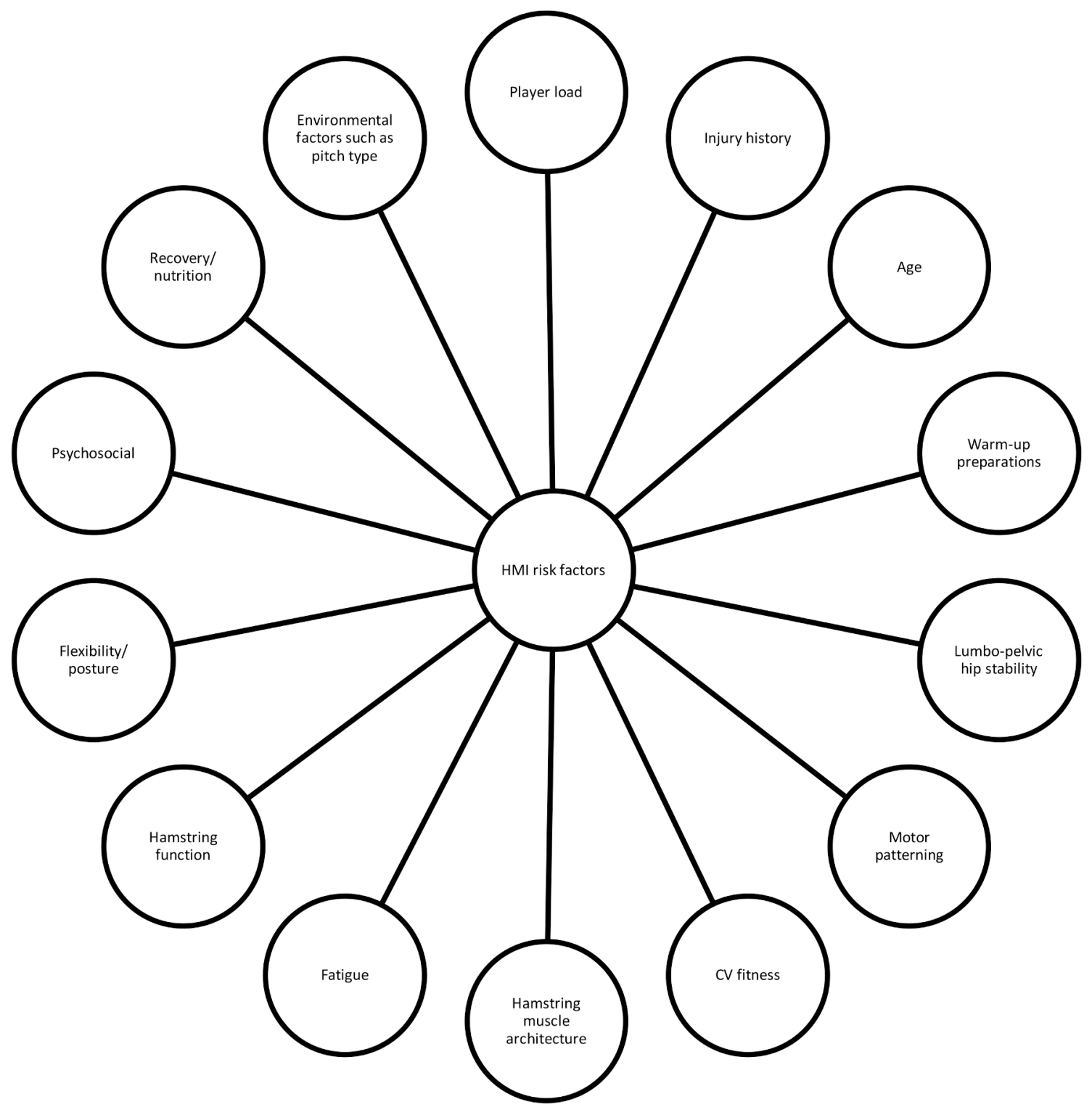

Figure 1 A diagram of factors to consider in hamstring muscle injury prevention. CV, cardiovascular.

Table 1 Risk factors linked to hamstring strain injuries, either through prospective, retrospective or anecdotal evidence. The table shows the typical manner in which our team would classify the risk factors associated with hamstring strain injury

\begin{tabular}{|c|c|c|c|}
\hline \multicolumn{2}{|l|}{ Important } & \multirow{2}{*}{$\begin{array}{l}\text { Semi-important } \\
\text { (implement where possible) }\end{array}$} & \multirow{2}{*}{$\begin{array}{l}\text { Recognised but does not inform } \\
\text { normal practice }\end{array}$} \\
\hline Specific risk factors & General risk factors & & \\
\hline Previous hamstring injury ${ }^{14-16}$ & ACWR (all parameters) ${ }^{48-51}$ & BFlh muscle/tendon architecture ${ }^{83-85}$ & Wisdom teeth/dental hygien $\mathrm{e}^{86}$ \\
\hline Weekly speed exposure ${ }^{44}$ & Functional strength ${ }^{72} 73$ & SIJ kinematics & \\
\hline \multirow[t]{6}{*}{ Hamstring fatigue resistance ${ }^{798287}$} & ACWR $(\text { HSR/vHSR })^{52}$ & Muscle fascicle length ${ }^{30}$ & \\
\hline & Psychosocial factors ${ }^{57}$ & Tib/Fib joint & \\
\hline & Time between games ${ }^{88}$ & & \\
\hline & Movement quality & & \\
\hline & Previous recent injury (any) & & \\
\hline & Aerobic fitness $^{74}$ & & \\
\hline
\end{tabular}

ACWR, acute:chronic workload ratio; BFlh, biceps femoris long head; Fib, fibula; HSR, high-speed running; SIJ, sacroiliac joint; Tib, tibia; TMJ, temporomandibular joint; vHSR, very high-speed running. 
information, in conjunction with appropriate ongoing injury reporting, screening and monitoring processes, provides the necessary information to create individualised training approaches to reduce player injury risk by targeting specific risk factors relevant to the players' profile, ${ }^{21}$ while also serving as benchmark criteria for return to play.

\section{Implement HSI prevention work as part of a complete injury prevention programme}

It is important that any HSI prevention programme be implemented as part of a complete injury prevention and performance programme. HSIs account for $12 \%$ of the total injuries sustained, ${ }^{22}$ and as such are the most common injury in elite football. However, they should also put in context alongside other injuries (which constitute the remaining 88\%). Thus, recognising the interplay between general risk factors for all injuries and maximising the crossover of interventions is important in programme design.

\section{OUR FIVE-POINT STRATEGY TO HSI PREVENTION IN ELITE FOOTBALL}

Below, we present our five-point HSI strategy, which contains research evidence as well as clinical experience in a truly evidence-based approach, generalisable to all elite-level teams. Additionally, this can be scaled appropriately to inform HSI prevention at all levels.

\section{Strengthen the hamstring muscles}

Injuries to the myofascial/muscletendon junction of the hamstrings are thought to occur when forces in excess of the mechanical limits of the tissue cause mechanical disruption. ${ }^{23-25}$ As such, a key prevention strategy to prevent HSIs should be to increase the capacity of the tissue, thereby raising the safety threshold for injury. The use of eccentric hamstring strength training is the most widely researched and recommended evidence-based strategy for HSI prevention and has been shown to significantly reduce the risk of primary and secondary HSIs (65\%-85\%). ${ }^{9} 1026$ Eccentric strength training also results in alterations of muscle architecture, specifically elongation of the biceps femoris long head (BFlh) fascicle length (16\%-34\% after 5-10 weeks of eccentric strength training), ${ }^{27} 28$ although not always. ${ }^{29}$ Professional players with short BFlh fascicles $(<10.6 \mathrm{~cm})$ were at fourfold greater risk of HSI than players with longer fascicles. ${ }^{30}$ HSI risk was reduced by $75 \%$ for every $0.5 \mathrm{~cm}$ increase in fascicle length. ${ }^{30}$
It is hypothesised that shorter fascicles, with fewer in series sarcomeres, may be more susceptible to being overstretched and having damage elicited via powerful eccentric actions, typical of the terminal swing phase of high-speed running (HSR). ${ }^{3031}$

Despite clear evidence for a role of eccentric strength training in HSI prevention, the actual evidence concerning the role of 'strength' in HSI risk is equivocal. ${ }^{14} 3032-35$ It is not clear whether it is changes in strength per se or fascicle length following eccentric strength training which supports the reduction in injury risk. Discrepancies between the role of strength and HSI could be explained partly by differences in constraints of the tasks (strength typically assessed under isolated conditions, eg, isokinetic dynamometry $^{32} 33$ vs injuries occurring during high-speed, high-force and highly complex tasks, eg, sprinting ${ }^{34}$ ). Possible factors which need to be considered when designing a strength programme include:

1. Hip extensor torques in sprint running exceed that of the knee flexor torques. ${ }^{36}$ The hamstring muscles contribute simultaneously to knee flexor and hip extensor torque. Weakness in hip extension strength was identified as a prospective risk factor for HSI in elite-level sprinters. ${ }^{37}$

2. Consideration needs to be given to all parts of the force-velocity curve in regard to its potential for athletic development and injury reduction. Indeed, force-velocity profiling has become more common in this environment in order to address areas of potential improvement in an individual as well as exercise selection adopted by the practitioner. Deficits in explosive strength would limit the ability to express maximal strength during sprinting. Indeed, previously injured hamstrings expressed deficits of $30 \%$ in eccentric rate of force development on return to sport after HSI. ${ }^{38}$

3. Poor intermuscular and intramuscular coordination can result in insufficient expression of isolated strength functionally. Suboptimal strength/activation of the stabiliser muscles can result in compensatory recruitment of the agonists and antagonists for dynamic joint stability (eg, to act as global stabilisers). This would result in compromised force output. ${ }^{3940}$ There must also be an acknowledgement of the continuum of complexity in regard to the coordination and activation patterns involved in actions like sprinting/ball striking versus the isolated strengthening that takes place in the gym. While both have their place, the progressions and constraints placed on the athlete are key to minimising the occurrence of HSI.

In terms of our approach to hamstring muscle strengthening, we, like many teams in elite football, value the role of eccentric strength training, ${ }^{41}$ but do not adopt the full NHE programme. ${ }^{11}$ Instead, we use a more holistic approach to hamstring muscle strengthening, ${ }^{13}$ one which recognises the need for optimal hamstring function (maximal and explosive strength across the force-velocity profile, balancing the focus on isometrics ${ }^{42}$ and eccentric and concentric actions). Although isometrics are perhaps less understood/researched than eccentrics, practice-based evidence has seen a big shift towards this in recent years. Additionally, it is important to recognise the need for both knee flexor and hip extensor strength; the similar morphological adaptations (hamstring eccentric strength and fascicle length changes) which accompany both knee dominant and hip dominant hamstring strengthening exercises ${ }^{27}$; similar adaptations to both low/high-volume $\mathrm{NHE}^{43}$; and the need for specificity in training. ${ }^{39}$ We focus primarily on the use of running (HSR, high speed acceleration and attaining peak running speed), given its high specificity (and possible performance benefits), the large hip and knee joint torques $^{36}$ and biomechanical symmetries to HSI mechanism and reduced barriers to its implementation. Admittedly, there is limited research into hamstring adaptations to sprint running (vs commonly assessed NHE), but recent research indicates that regularly achieving peak or near-peak running speeds in training is associated with a lower risk of HSI. ${ }^{44}$ As such, we aim to expose all players to within $95 \%$ of maximum speed one to two times per week. This programme is supported by gym-based individualised strengthening programmes (balancing the combination of hip and knee dominant and isolated and compound exercises) depending on player and coach buy-in and current playing status (eg, additional gym-based hamstring eccentrics are not sensible during congested match play in regular starting players). Also, injury history and the player profile support the programme design. We specifically look for players who have poor eccentric hamstring strength $(<350 \mathrm{~N})^{30}$ or a right to left asymmetry in eccentric strength (typically $>10 \%$ although we state this with caution as there are individuals who naturally appear to have a greater deficit 
than this up to $25 \%{ }^{45} 46$ ), assessed using the NordBord. We currently use fatigue resistance (single leg bridge to capacity test ${ }^{47}$ ) primarily for return to play monitoring.

Optimise the training balance: carefully monitor players and ensure optimal recovery strategies

Perhaps the most important element of preventing injuries in elite football lies in optimally managing player load. There is emerging evidence that heightened ACWR which accompanies congested match play is one of the key factors leading to increased injury risk. ${ }^{48-51}$ Exposing players to large and rapid increases in HSR distances above their two yearly session average was shown to increase the odds of HSI. In particular, elevated HSR in the week before injury demonstrated a 6.4 times increased risk of HSI. ${ }^{52}$ Previous research by our group indicated higher accumulated and acute workloads were associated with a greater injury risk, but progressive increases in chronic workload may develop the players' physical tolerance to higher acute loads and resilience to injury risk. ${ }^{49}$ Other researchers have also found high training loads to be protective in elite team sport. ${ }^{51}$ In terms of ACWR, it appears that HSR may be more predictive of HSI risk ${ }^{52}$ and exposing players to large and rapid increases in training above what they are habitually used to increases the odds of sustaining an HSI. A high ACWR may be in part due to a low chronic training (eg, low denominator) or congested match play (eg, typical of the winter periods or when involved in European or domestic cup match play).

In terms of our approach to managing players' training workloads, we monitor the ACWR using Global Positioning System technology (and TRACAB for match loads), limiting exposure to high ACWR $(<1.4$, although this appears to be largely individual), particularly in HSR $(>5.5 \mathrm{~m} / \mathrm{s}$ ) and very HSR (vHSR; $>7 \mathrm{~m} / \mathrm{s}$ ). This should be achieved by progressively increasing player training load (avoiding spikes in acute loading) to achieve longterm moderate to high chronic training loads, which aim to prepare the players for the equivalent of three matches worth of load per week (figure 2). Thus, during fixture congested periods, the players have a greater tolerance and robustness for the heightened loads. Additionally, while the load increases are progressive, they involve week-to-week fluctuations, involving deloading periods for adequate rest and recovery, as well as periods of overloading to produce adaptation ${ }^{53}$ (figure 2). Within this, we acknowledge that consistently high loads may lead to other stress-related injuries and that an individual's physiological response to spikes in ACWR may vary; thus, experience in managing individual responses should still be considered, as should individual banding of speed thresholds to better reflect energy system output.

Football training typically mimics the physical intensity and movement patterns of match play, but can often result in limited exposure to HSR/vHSR due to the use of smaller areas. Match play represents the largest stimulus in terms of HSR and thus balancing training to reflect match play HSR load is important. Anecdotally, those players often at risk of HSI are regular non-starters or players returning from injury, who are suddenly required for a period of congested match play. In these players, there is a need to individualise their training, closely monitoring their HSR and peak running speeds in training and providing top-ups to maintain sufficient acute and chronic workloads in the absence of first team match play. These top-ups may take the form of additional running during or after training, use of additional training sessions (eg, match day +1 , or additional sessions in the afternoon, for example) and/or organised matches (eg, training/

\section{ACUTE:CHRONIC HSR}

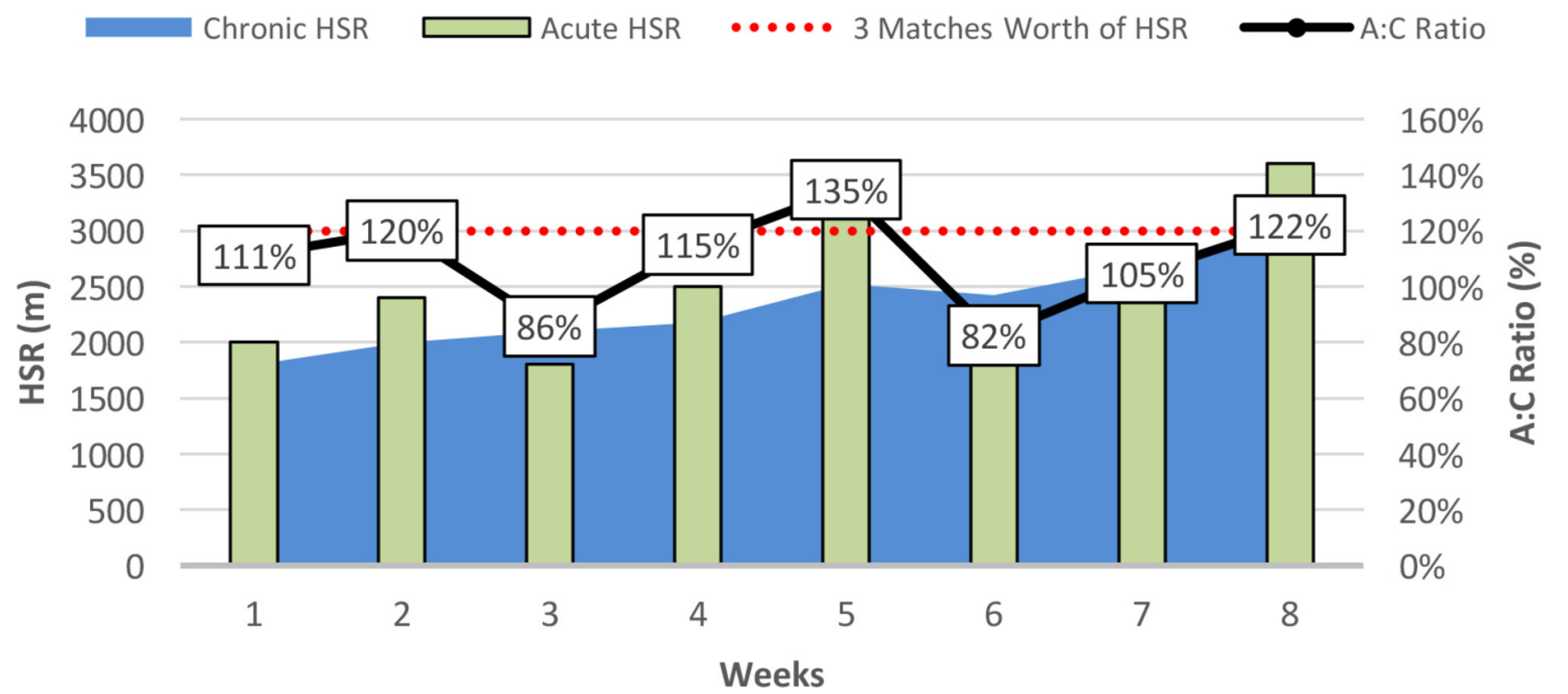

Figure 2 Graphical representation of the progressive increase of a player's chronic high-speed running over the course of an 8-week intervention. The player begins with a chronic load of $2000 \mathrm{~m}$ representing a two-match load and is trained with the goal of progressively increasing his chronic training load, adopting a structured periodisation model to fluctuate the weekly training demands to achieve a chronic high-speed running of three matches equivalent per week. The current programme used a 2-week overload and 1-week deload maintaining the acute:chronic workload ratio below 1.4 (peak 1.35) and deload week remaining above 0.8 (lowest 0.82 ) to prevent acute heightened risk of injury. A, acute; C, chronic; HSR, highspeed running. 
development team matches). Additionally, substitutes who play little or no minutes complete HSR or speed exposure sessions (specific to the individual needs) immediately after game, to allow them to maintain the same schedule as the playing squad. Although this is an area which we need to gain a better understanding of, greater knowledge of an individual's typical demands in training/match play may help us keep them appropriately conditioned. Individualised speed zones based off maximum speed can help ensure the player is monitored relative to their own physical capabilities/energy systems, and thus their outputs are not over/underestimated relative to them. During periods of congested match play, it is essential to have optimal strategies in place to accelerate recovery (eg, hydrotherapy, nutrition, rest/sleep, cryotherapy, cold water immersion and soft tissue massage), and limit possible residual strength loss into the next match. ${ }^{54-56}$

An additional important element of managing player load is to recognise this is not just physical, but can also be psychological/emotional. Psychosocial factors (ie, stressful life events) may contribute to injury risk. ${ }^{57}$ Elite football can be highly stressful, and as such recognising psychological load may also be important. Therefore, load monitoring strategies need to encompass all forms of load (eg, wellness questionnaires, sleep, ratings of perceived exertions, training and match loads). Additional in-depth analysis (eg, assessment of hamstring isometric strength after match play $)^{58}$ should be undertaken with highrisk players (eg, older and/or previously injured players $\left.{ }^{14-16}\right)$, which can support an optimal load management strategy and possible early warning system.

\section{Implement a lumbopelvic hip stability programme}

A widely held belief in elite sport is that that lumbopelvic hip stability training is important in the prevention of HSI. However, its use has recently been questioned due to a very small amount of evidence to support this. ${ }^{59}$ However, based on the available theory, positive anecdotal experience and a link with other injuries, ${ }^{60}$ we promote its inclusion as part of a holistic approach to preventing HSIs. For instance, the pelvis is responsible for load transfer between the lower limbs and the spine. ${ }^{61}$ Aberrant pelvic motion, specifically anterior pelvic tilt, or trunk motion such as lateral trunk tilt during sprint running is thought to increase HSI risk. ${ }^{62-64}$ Leg-length asymmetries are associated with innominate bone rotation ${ }^{64}$ and an asymmetry greater than $1.8 \mathrm{~cm}$ is linked with a fourfold heightened risk of HSI. ${ }^{65}$ An uncontrolled anterior pelvic tilt during sprint running can elicit substantial stretch on the hamstring muscles, thereby increasing tension on the BFlh in terminal swing phase. ${ }^{66}$ Hip flexor tightness is a prospective risk factor for $\mathrm{HSIs}^{15}{ }^{67}$ and is associated with an anterior pelvic tilt in sprint running, increased stretch on the hamstring muscle at late-swing phase and also associated with inhibition of the gluteus maximus, via reciprocal muscle inhibition and subsequent synergistic dominance of the hamstring muscles. ${ }^{68}{ }^{69}$ Hip extension torques can exceed double that of knee flexion torques during sprinting, ${ }^{36}$ and so reduced strength or activation of the gluteus maximus (both identified as prospective risk factors for $\mathrm{HSI})^{37} 70$ would elevate the demands placed on the hamstring muscles. It appears that altered lumbopelvic stability, alignment and coordination can both limit the expression of hamstring strength at longer muscle lengths (eg, terminal swing phase) and simultaneously elevate their demands.

Comerford and Mottram ${ }^{71}$ offer a framework for the assessment and retraining of uncontrolled movement, when applied to the lumbopelvic hip complex. This offers a logical systembased approach which can assist the practitioner in establishing the site and direction of uncontrolled movement in both low/high-load situations. Practitioners should consider the training dichotomy between (1) the efficiency of local stabilising muscles, tonic in nature with slow motor units, which are used for non-fatiguing functional tasks, controlling translation and contributing to postural control, versus (2) high threshold, global stabilising muscles, whose predominant fast motor units are phasic in nature and capable of generating high force to limit or decelerate range of motion. ${ }^{68}$ Many methods exist for training stability within the lumbopelvic hip complex. Floor-based exercises, Pilates adjuncts or machines may be convenient methods to isolate movements, challenge postural awareness and ability to dissociate, and build muscle capacity; and all have a component part in our practice of HSI prevention. A key element of these isolated exercises is to ensure optimal recruitment of the target muscles, recognising the possibility of primary agonist inhibition and subsequent synergistic dominance ${ }^{69}$ Yet the law of specificity should be respected to ensure transference to athletic tasks (see point 5).
Develop players' physical conditioning

There is evidence indicating an important role of player's physical conditioning (eg, general lower body compound strength and cardiovascular (CV) fitness) in reducing risk of injury. Across a range of sports, those with superior physical qualities are more robust to injury. ${ }^{72-74}$ Additionally, the implementation of strength training has been shown to reduce injury risk. ${ }^{75}$ Elevated ACWR is associated with injury, ${ }^{48-51}$ but those athletes who are stronger ${ }^{73}$ and have superior CV fitness ${ }^{74}$ are better able to tolerate elevated ACWR.

Furthermore, lower body compound strength is essential for sports performance during explosive tasks such as sprint running and jumping, ${ }^{76}$ while sufficient CV fitness is essential to cope with the movement demands without adverse fatigue and its associated negative consequences (eg, compromised player biomechanics and neuromuscular control/ capacity to produce force). ${ }^{77}{ }^{78}$ It is also known that fatigued muscle has reduced ability to absorb energy before reaching the amount of stretch that results in injury. ${ }^{79}$ Players will undergo on-field testing at various stages of the season. Their performance to exhaustion on the Yo-Yo Intermittent Recovery Level 1 test will provide useful information as to the players' aerobic/anaerobic capacity. The same test can be repeated at a submaximal level to a predetermined point on the test to provide the practitioner with useful data in regard to the players' heart rate (HR) response and subsequent HR recovery. ${ }^{80}$

Our programme consists of a general strength and conditioning approach for both performance optimisation and injury risk reduction. Often training and match play provide a sufficient stimulus for CV adaptation/maintenance. However, it is important to monitor players' HR responses to training and where necessary provide additional off-feet conditioning (eg, we incorporate hypoxic interval-based high-intensity session on the bike/crosstrainer, achieving set targets of HR). Off-feet conditioning is also important for the load compromised player (eg, less robust players with high risk of injury or extensive injury history or the player returning from injury, and as such typically having a lower chronic training load) in reducing injury risk. We also use this approach with target red zone (>85\% max HR) minutes, training impulse, or sessions that match the output of the training group/high-intensity periods of the game to replicate the energy system demands. 
Incorporate a focus on movement quality

We have a philosophy of assessing/ improving the fundamental movement patterns (squat, step lunge, hinge, jump, land). Such movements need to be performed in different directions, speeds and planes to improve athletic movement and reduce the risk of potential injury. ${ }^{81}$ Practising athletic movement challenges coordination, timing and neuromuscular control, and is associated with an increased ability to express and apply strength functionally (eg, in sporting-type movements such as running). ${ }^{39} 40 \quad 82$ Programmes incorporating athletic movement with good technique and repetition may enhance neuromuscular control and sequencing. Specific drills which break down components of the running action, focusing on a stable pelvic position, and upper and lower limb position during marching, skipping and running tasks form an important component of our conditioning continuum. These qualities are trained in a variety of ways as part of on-field warm-ups, physical development sessions in the gym and preactivation sessions prior to regular football/skillbased training. A graded approach which establishes good technique at slower speeds and simple tasks establishes a basic competence which supports the development of drill speed and complexity, further challenging neuromuscular development of strength, control and sequencing within athletic tasks, which we feel supports both performance enhancement and injury reduction.

Anecdotally, these drills naturally assist the development of linear speed and acceleration programmes and seem of value improving pelvic and hip position, as well as upper and lower limb position, particularly at speed. It should be noted however that they are biased towards sagittal plane horizontal movement, and that field-based sports which are inherently multidirectional in nature require support in this approach with movement quality drills which develop jumping, landing, deceleration and change of direction.

\section{CONCLUSION}

This paper presents our five-point strategy for preventing HSIs. We believe that high HSI rates are in part due to the recommendation of a simple single component approach to a complex multifactorial problem. We suggest from our learning experiences that there is a need for a holistic approach that translates existing knowledge on HSI injury risk and applies this to a football context. However, it is important to recognise the contextual factors which can influence the adoption, implementation and sustained use of such a programme. We advise those in football when designing their HSI prevention strategy to gain key stakeholder buy-in, consider HSIs as part of an overall prevention strategy and treat the individual player where possible. We do not seek to discredit the use of any one particular programme in HSI prevention; we suggest rather than implement a single modal intervention, we encourage a holistic approach and consider the complex interaction of multiple risk factors in HSI alongside our five-point strategy. This approach is not wholly evidence based, but we believe this represents a judicious approach to HSI prevention, which builds on our shared anecdotal experience and remains evidence informed. Our goal is to share our approach as we believe it can form part of the journey towards the current best practice approach to HSI prevention at both elite and other levels of football.

Contributors MB proposed the topic of the paper and wrote the first version as a follow-up to a previous editorial from the group. All other authors provided intellectual contributions as part of the redrawing process in each of their respective areas of expertise.

Funding The authors have not declared a specific grant for this research from any funding agency in the public, commercial or not-for-profit sectors.

\section{Competing interests None declared.}

Patient consent Not required.

Provenance and peer review Not commissioned; externally peer reviewed.

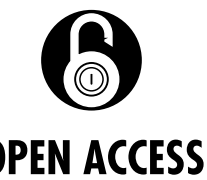

Open access This is an open access article distributed in accordance with the Creative Commons Attribution Non Commercial (CC BY-NC 4.0) license, which permits others to distribute, remix, adapt, build upon this work non-commercially, and license their derivative works on different terms, provided the original work is properly cited, appropriate credit is given, any changes made indicated, and the use is non-commercial. See: http:// creativecommons.org/licenses/by-nc/4.0/.

(c) Author(s) (or their employer(s)) 2019. Re-use permitted under CC BY-NC. No commercial re-use. See rights and permissions. Published by BMJ.

\section{Check for updates}

To cite Buckthorpe M, Wright S, Bruce-Low S, et al. Br J Sports Med 2019;53:449-456.

Accepted 14 October 2018

Published Online First 9 November 2018

Br J Sports Med 2019;53:449-456.

doi:10.1136/bjsports-2018-099616
REFERENCES

1 Hägglund M, Waldén M, Magnusson $\mathrm{H}$, et al. Injuries affect team performance negatively in professional football: an 11-year follow-up of the UEFA Champions League injury study. Br J Sports Med 2013;47:738-42.

2 Hickey J, Shield AJ, Williams MD, et al. The financial cost of hamstring strain injuries in the Australian Football League. Br J Sports Med 2014;48:729-30.

3 Ekstrand J, Waldén M, Hägglund M. Hamstring injuries have increased by $4 \%$ annually in men's professional football, since 2001: a 13-year longitudinal analysis of the UEFA Elite Club injury study. Br J Sports Med 2016;50:731-7

4 Barnes C, Archer DT, Hogg B, et al. The evolution of physical and technical performance parameters in the English Premier League. Int J Sports Med 2014;35:1095-100

5 Brukner P, Nealon A, Morgan C, et al. Recurrent hamstring muscle injury: applying the limited evidence in the professional football setting with a seven-point programme. Br J Sports Med 2014;48:929-38.

6 Buckthorpe M, Gimpel M, Wright S, et al. Hamstring muscle injuries in elite football: translating research into practice. Br J Sports Med 2018;52:628-9.

7 Mendiguchia J, Alentorn-Geli E, Brughelli M. Hamstring strain injuries: are we heading in the right direction? Br J Sports Med 2012;46:81-5.

8 Mendiguchia J, Martinez-Ruiz E, Edouard P, et al. A multifactorial, criteria-based progressive algorithm for hamstring injury treatment. Med Sci Sports Exerc 2017:49:1482-92.

9 Goode AP, Reiman MP, Harris L, et al. Eccentric training for prevention of hamstring injuries may depend on intervention compliance: a systematic review and meta-analysis. Br J Sports Med 2015;49:349-56.

10 Petersen J, Thorborg K, Nielsen MB, et al. Preventive effect of eccentric training on acute hamstring injuries in men's soccer: a cluster-randomized controlled trial. Am J Sports Med 2011;39:2296-303.

11 Bahr R, Thorborg K, Ekstrand J. Evidence-based hamstring injury prevention is not adopted by the majority of Champions League or Norwegian Premier League football teams: the Nordic Hamstring survey. Br J Sports Med 2015:49:1466-71.

12 Bekker S, Paliadelis P, Finch CF. The translation of sports injury prevention and safety promotion knowledge: insights from key intermediary organisations. Health Res Policy Syst 2017;15:25.

13 Oakley AJ, Jennings J, Bishop CJ. Holistic hamstring health: not just the Nordic hamstring exercise. $\mathrm{Br} J$ Sports Med 2018;52:816-7.

14 Arnason A, Sigurdsson SB, Gudmundsson A, et al. Risk factors for injuries in football. Am J Sports Med 2004:32:5-16.

15 Freckleton G, Pizzari T. Risk factors for hamstring muscle strain injury in sport: a systematic review and meta-analysis. Br J Sports Med 2013;47:351-8.

16 Hägglund $M$, Waldén $M$, Ekstrand J. Previous injury as a risk factor for injury in elite football: a prospective study over two consecutive seasons. Br J Sports Med 2006:40:767-72

17 Bittencourt NFN, Meeuwisse WH, Mendonça LD, et al. Complex systems approach for sports injuries: moving from risk factor identification to injury pattern recognition-narrative review and new concept. $\mathrm{Br} J$ Sports Med 2016;50:1309-14.

18 McCall A, Davison M, Carling C, et al. Can offfield 'brains' provide a competitive advantage in professional football? Br J Sports Med 2016;50:710-2.

19 Ekstrand J, Lundqvist D, Lagerbäck L, et al. Is there a correlation between coaches' leadership styles and injuries in elite football teams? A study of 36 elite teams in 17 countries. Br J Sports Med 2018;52:527-31.

20 Ekstrand J, Lundqvist D, Davison $\mathrm{M}$, et al. Communication quality between the medical team and the head coach/manager is associated with injury 
burden and player availability in elite football clubs. $\mathrm{Br}$ J Sports Med 2018:bjsports-2018-099411.

21 Verhagen E, van Dyk N, Clark N, et al. Do not throw the baby out with the bathwater; screening can identify meaningful risk factors for sports injuries. $\mathrm{Br} J$ Sports Med 2018:52:1223-4.

22 Ekstrand J, Hägglund M, Waldén M. Epidemiology of muscle injuries in professional football (soccer). Am J Sports Med 2011;39:1226-32.

23 Askling CM, Tengvar M, Saartok T, et al. Acute firsttime hamstring strains during slow-speed stretching: clinical, magnetic resonance imaging, and recovery characteristics. Am J Sports Med 2007;35:1716-24.

24 Askling CM, Tengvar M, Saartok T, et al. Acute firsttime hamstring strains during high-speed running: a longitudinal study including clinical and magnetic resonance imaging findings. Am J Sports Med 2007;35:197-206

25 Askling CM, Tengvar M, Thorstensson A. Acute hamstring injuries in Swedish elite football: a prospective randomised controlled clinical trial comparing two rehabilitation protocols. Br I Sports Med 2013:47:953-9.

26 Tyler TF, Schmitt BM, Nicholas SJ, et al. Rehabilitation after hamstring-strain injury emphasizing eccentric strengthening at long muscle lengths: Results of longterm follow-up. J Sport Rehabil 2017;26:131-40.

27 Bourne MN, Duhig SJ, Timmins RG, et al. Impact of the Nordic hamstring and hip extension exercises on hamstring architecture and morphology: implications for injury prevention. Br I Sports Med 2017:51:469-77.

28 Potier TG, Alexander CM, Seynnes OR. Effects of eccentric strength training on biceps femoris muscle architecture and knee joint range of movement. Eur $J$ Appl Physiol 2009;105:939-44.

29 Seymore KD, Domire ZJ, DeVita P, et al. The effect of Nordic hamstring strength training on muscle architecture, stiffness, and strength. Eur J Appl Physiol 2017;117:943-53.

30 Timmins RG, Bourne MN, Shield AJ, et al. Short biceps femoris fascicles and eccentric knee flexor weakness increase the risk of hamstring injury in elite football (soccer): a prospective cohort study. Br J Sports Med 2016;50:1524-35.

31 Brockett CL, Morgan DL, Proske U. Human hamstring muscles adapt to eccentric exercise by changing optimum length. Med Sci Sports Exerc 2001;33:783-90.

32 Croisier JL, Ganteaume S, Binet J, et al. Strength imbalances and prevention of hamstring injury in professional soccer players: a prospective study. Am J Sports Med 2008;36:1469-75.

33 van Dyk N, Bahr R, Whiteley R, et al. Hamstring and quadriceps isokinetic strength deficits are weak risk factors for hamstring strain injuries. Am I Sports Med 2016:44:1789-95.

34 Arnason A, Andersen TE, Holme I, et al. Prevention of hamstring strains in elite soccer: an intervention study. Scand I Med Sci Sports 2008;18:40-8.

35 Woods C, Hawkins RD, Maltby S, et al. The Football Association Medical Research Programme: an audit of injuries in professional football--analysis of hamstring injuries. Br J Sports Med 2004;38:36-41.

36 Higashihara A, Nagano Y, Ono T, et al. Differences in hamstring activation characteristics between the acceleration and maximum-speed phases of sprinting. J Sports Sci 2018;36:1313-8.

37 Sugiura Y, Saito T, Sakuraba K, et al. Strength deficits identified with concentric action of the hip extensors and eccentric action of the hamstrings predispose to hamstring injury in elite sprinters. J Orthop Sports Phys Ther 2008;38:457-64.

38 Opar DA, Williams MD, Timmins RG, et al. Rate of torque and electromyographic development during anticipated eccentric contraction is lower in previously strained hamstrings. Am I Sports Med 2013;41:116-25.
39 Buckthorpe MW, Erskine R, Fletcher G, et al. Neural adaptations explain the task specificity of strength changes after resistance training. Scand J Med Sci Sports 2015:25:640-9.

40 Cacchio A, Don R, Ranavolo A, et al. Effects of 8-week strength training with two models of chest press machines on muscular activity pattern and strength. $J$ Electromyogr Kinesiol 2008;18:618-27.

41 McCall A, Carling C, Nedelec M, et al. Risk factors, testing and preventative strategies for non-contact injuries in professional football: current perceptions and practices of 44 teams from various premier leagues. Br J Sports Med 2014;48:1352-7.

42 Van Hooren B, Bosch F. Is there really an eccentric action of the hamstrings during the swing phase of high-speed running? Part II: Implications for exercise. $J$ Sports Sci 2017:35:2322-33.

43 Presland J, Timmins R, Bourne M, et al. The effect of high or low volume Nordic hamstring exercise training on eccentric strength and biceps femoris long head architectural adaptations. Scand J Med Sci Sports 2018:28:1775-83

44 Malone S, Roe M, Doran DA, et al. High chronic training loads and exposure to bouts of maxima velocity running reduce injury risk in elite Gaelic football. J Sci Med Sport 2017;20:250-4.

45 Bourne MN, Opar DA, Williams MD, et al. Eccentric knee flexor strength and risk of hamstring injuries in rugby union: a prospective study. Am I Sports Med 2015;43:2663-70

46 Opar DA, Williams MD, Timmins RG, et al. Eccentric hamstring strength and hamstring injury risk in Australian footballers. Med Sci Sports Exerc 2015;47:857-65.

47 Freckleton G, Cook J, Pizzari T. The predictive validity of a single leg bridge test for hamstring injuries in Australian Rules Football Players. Br I Sports Med 2014:48:713-7.

48 Blanch P, Gabbett TJ. Has the athlete trained enough to return to play safely? The acute:chronic workload ratio permits clinicians to quantify a player's risk of subsequent injury. Br I Sports Med 2016;50:471-5.

49 Bowen L, Gross AS, Gimpel M, et al. Accumulated workloads and the acute:chronic workload ratio relate to injury risk in elite youth football players. Br J Sports Med 2017:51:452-9.

50 Gabbett TJ. The training-injury prevention paradox: should athletes be training smarter and harder? $\mathrm{Br} J$ Sports Med 2016;50:273-80.

51 Hulin BT, Gabbett TJ, Caputi P, et al. Low chronic workload and the acute:chronic workload ratio are more predictive of injury than between-match recovery time: a two-season prospective cohort study in elite rugby league players. Br J Sports Med 2016;50:1008-12.

52 Duhig S, Shield AJ, Opar D, et al. Effect of high-speed running on hamstring strain injury risk. Br I Sports Med 2016:50:1536-40.

53 SELYE H. The general adaptation syndrome and the diseases of adaptation. J Clin Endocrinol Metab $1946 ; 6: 117-230$

54 Fonda B, Sarabon N. Effects of whole-body cryotherapy on recovery after hamstring damaging exercise: a crossover study. Scand I Med Sci Sports 2013:23:e270-8.

55 Vaile J, Halson S, Gill N, et al. Effect of hydrotherapy on recovery from fatigue. Int I Sports Med 2008;29:539-44.

56 Reilly T, Cable NT, Dowzer CN. Does deep-water running aid recovery from stretch-shortening cycle exercise? Communication to the Sixth Annual Conference of the European College of Sport Science, Ko" In, Germany, July. 2001Stone MH, Moir G, Glaister $M$, Sanders R. How much strength is necessary? Phys Ther Sport;2002:88-96.

57 Ivarsson A, Johnson U, Andersen MB, et al. Psychosocial factors and sport injuries: Metaanalyses for prediction and prevention. Sports Med 2017;47:353-65.
58 Schache AG, Crossley KM, Macindoe IG, et al. Can a clinical test of hamstring strength identify football players at risk of hamstring strain? Knee Surg Sports Traumatol Arthrosc 2011:19:38-41.

59 Shield AJ, Bourne MN. Hamstring injury prevention practices in elite sport: Evidence for eccentric strength vs. Lumbo-pelvic training. Sports Med 2018:48:513-24.

60 Huxel Bliven KC, Anderson BE. Core stability training for injury prevention. Sports Health 2013:5:514-22.

61 Lee DG, Lee LJ. Saunders WB, ed. Integrated, multimodal approach to the treatment of pelvic girdle pain and dysfunctionMagee ed. : Treatment of Pathology and Injuries, 2000:III: 473-84.

62 Chumanov ES, Heiderscheit BC, Thelen DG. The effect of speed and influence of individual muscles on hamstring mechanics during the swing phase of sprinting. J Biomech 2007;40:3555-62.

63 Schuermans J, Van Tiggelen D, Palmans T, et al. Deviating running kinematics and hamstring injury susceptibility in male soccer players: Cause or consequence? Gait Posture 2017:57:270-7.

64 Sherry MA, Best TM. A comparison of 2 rehabilitation programs in the treatment of acute hamstring strains. $J$ Orthop Sports Phys Ther 2004;34:116-25.

65 Cummings G, Scholz JP, Barnes K. The effect of imposed leg length difference on pelvic bone symmetry. Spine 1993;18:368-73.

66 Fousekis K, Tsepis E, Poulmedis P, et al. Intrinsic risk factors of non-contact quadriceps and hamstring strains in soccer: a prospective study of 100 professional players. Br J Sports Med 2011;45:709-14.

67 Gabbe BJ, Finch CF, Bennell KL, et al. Risk factors for hamstring injuries in community level Australian football. Br J Sports Med 2005;39:106-10.

68 Mills M, Frank B, Goto S, et al. Effect of restricted hip flexor muscle length on hip extensor muscle activity and lower extremity biomechanics in collegeaged female soccer players. Int I Sports Phys Ther 2015;10:946-54

69 Sahrmann S. Diagnosis and Treatment of Movement Impairment Syndromes. Oxford, UK: Elsevier Health Sciences, 2013.

70 Schuermans J, Danneels L, Van Tiggelen D, et al. Proximal neuromuscular control protects against hamstring injuries in male soccer players: a prospective study with electromyography time-series analysis during maximal sprinting. Am I Sports Med 2017:45:1315-25.

71 Comerford MJ, Mottram SL. Movement and stability dysfunction--contemporary developments. Man Ther 2001;6:15-26.

72 Gabbett TJ, Ullah S, Finch CF. Identifying risk factors for contact injury in professional rugby league players-application of a frailty model for recurrent injury. I Sci Med Sport 2012;15:496-504

73 Malone S, Hughes B, Doran DA, et al. Can the workload-injury relationship be moderated by improved strength, speed and repeated-sprint qualities? I Sci Med Sport 2018

74 Malone S, Roe M, Doran DA, et al. Protection against spikes in workload with aerobic fitness and playing experience: the role of the acute:chronic workload ratio on injury risk in elite gaelic football. Int I Sports Physiol Perform 2017;12:393-401.

75 Lauersen JB, Bertelsen DM, Andersen LB. The effectiveness of exercise interventions to prevent sports injuries: a systematic review and meta-analysis of randomised controlled trials. Br I Sports Med 2014:48:871-7.

76 Wisløff U, Castagna C, Helgerud J, et al. Strong correlation of maximal squat strength with sprint performance and vertical jump height in elite soccer players. Br J Sports Med 2004;38:285-8.

77 Santamaria LJ, Webster KE. The effect of fatigue on lower-limb biomechanics during single-limb landings: a systematic review. J Orthop Sports Phys Ther 2010;40:464-73. 
78 Buckthorpe M, Pain MT, Folland JP. Central fatigue contributes to the greater reductions in explosive than maximal strength with high-intensity fatigue. Exp Physiol 2014;99:964-73.

79 Mair SD, Seaber AV, Glisson RR, et al. The role of fatigue in susceptibility to acute muscle strain injury. Am J Sports Med 1996;24:137-43.

80 Bradley PS, Mohr M, Bendiksen M, et al. Sub-maximal and maximal $Y_{0}-Y_{0}$ intermittent endurance test level 2: heart rate response, reproducibility and application to elite soccer. Eur J App/ Physiol 2011;111:969-78.

81 Malliaropoulos N, Mendiguchia J, Pehlivanidis H, et al. Hamstring exercises for track and field athletes: injury and exercise biomechanics, and possible implications for exercise selection and primary prevention. $\mathrm{Br} J$ Sports Med 2012;46:846-51.
82 Bobbert MF, Van Soest AJ. Effects of muscle strengthening on vertical jump height: a simulation study. Med Sci Sports Exerc 1994;26:1012-20.

83 Evangelidis PE, Massey GJ, Pain MT, et al. Biceps femoris aponeurosis size: a potential risk factor for strain injury? Med Sci Sports Exerc 2015;47:1383-9.

84 Fiorentino NM, Blemker SS. Musculotendon variability influences tissue strains experienced by the biceps femoris long head muscle during high-speed running. J Biomech 2014;47:3325-33.

85 Rehorn MR, Blemker SS. The effects of aponeurosis geometry on strain injury susceptibility explored with a 3D muscle model. J Biomech 2010;43:2574-81.

86 Solleveld H, Goedhart A, Vanden Bossche L. Associations between poor oral health and reinjuries in male elite soccer players: a cross-sectional self-report study. BMC Sports Sci Med Rehabil 2015;7:11

87 Greig M. The influence of soccer-specific fatigue on peak isokinetic torque production of the knee flexors and extensors. Am J Sports Med 2008;36:1403-9.

88 Bengtsson $\mathrm{H}$, Ekstrand J, Waldén $\mathrm{M}$, et al. Muscle injury rate in professional football is higher in matches played within 5 days since the previous match: a 14-year prospective study with more than 130000 match observations. Br J Sports Med 2018;52:1116-22.

89 Small K, McNaughton L, Greig M, et al. Effect of timing of eccentric hamstring strengthening exercises during soccer training: implications for muscle fatigability. J Strength Cond Res 2009;23:1077-83. 